\title{
RUPTURE OF THE STOMACH IN THE NEWBORN DUE TO CONGENITAL DEFECTS IN THE GASTRIC MUSCULATURE
}

\author{
BY \\ P. C. MacGillivray, A. M. Stewart and A. MacFARlane \\ From the Eastern General Hospital, Edinburgh
}

(RECEIVED FOR PUBLICATION OCTOBER 25, 1955)

Gastric perforation in the newborn is rare. In the infant described here it occurred because there were defects in the wall of the stomach, and the case is reported because of the help it may give in the management and understanding of similar emergencies.

\section{Case Report}

A male infant weighing $5 \mathrm{lb} .7 \mathrm{oz} .(2.49 \mathrm{~kg}$.) was delivered spontaneously after a normal labour. He was the mother's second child; the pregnancy was uneventful and labour began at term.

At birth the infant was pale and respirations were laboured. A few hours after delivery he vomited about $2 \mathrm{ml}$. of altered blood and was therefore given $10 \mathrm{mg}$. of vitamin $\mathrm{K}$ intramuscularly. With warmth and the administration of oxygen there was an improvement in his condition, which was maintained the next day though he remained limp and reluctant to feed.

Forty-eight hours after delivery the infant was still not feeding well, and $1 \mathrm{oz}$. of expressed breast milk was given through an intragastric rubber tube. A similar feed was given three hours later. Following it, he vomited and the abdomen was noted to be a little distended. The vomitus consisted largely of milk, but there were a few streaks of fresh blood in it. Three hours later a further tube feed was given, and shortly after this the baby collapsed. He was pale and the abdomen was grossly distended and tympanitic. The scrotum was large and translucent. With pressure it emptied of gas with a gurgling sound, and filled again when released. Crepitant subcutaneous emphysema was felt in the lower abdominal wall extending from the pubis to the umbilicus, mainly on the left side.

Plain radiographs were taken in the erect and inverted positions (Figs. 1, 2, 3, 4). These showed a gross pneumoperitoneum with gas in the scrotum and in the subcutaneous tissues of the lower abdominal wall. There was some free fluid in the peritoneal cavity and gas was clearly seen in the lower sigmoid colon and rectum.

The clinical and radiological evidence of such a large pneumoperitoneum without an intestinal obstruction suggested a high perforation, probably of the stomach.

At laparotomy (Mr. J. J. Mason Brown) gas under considerable tension escaped and the peritoneal cavity was seen to contain bile-stained fluid with a few flakes of milk. A rupture of the stomach was found which extended over the anterior wall from the greater curvature to the lower oesophagus. The upper half involved all coats of the gastric wall, but in the lower half the mucosa was intact. This rupture was closed with silk sutures without great difficulty, though it was noted that the gastric wall was thin and the sutures were liable to cut out. After the operation the infant's condition was

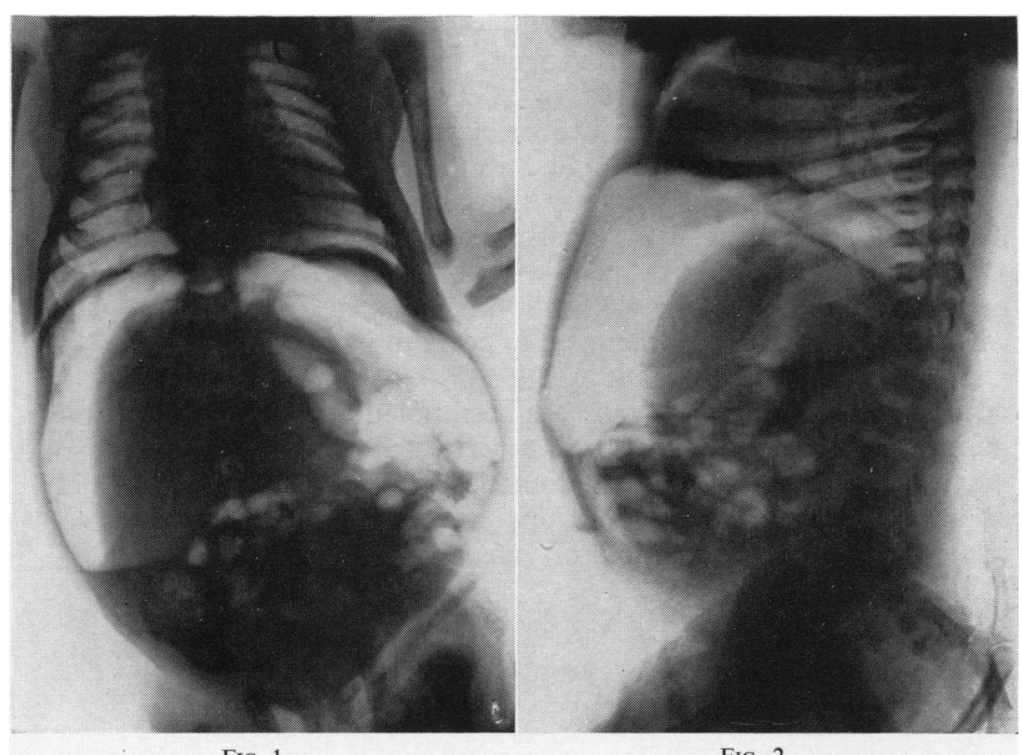

FIGS. 1 and 2.-Radiograph, antero-posterior and lateral, in the erect position, showing gross pneumoperitoneum and intraperitoneal fluid level. 


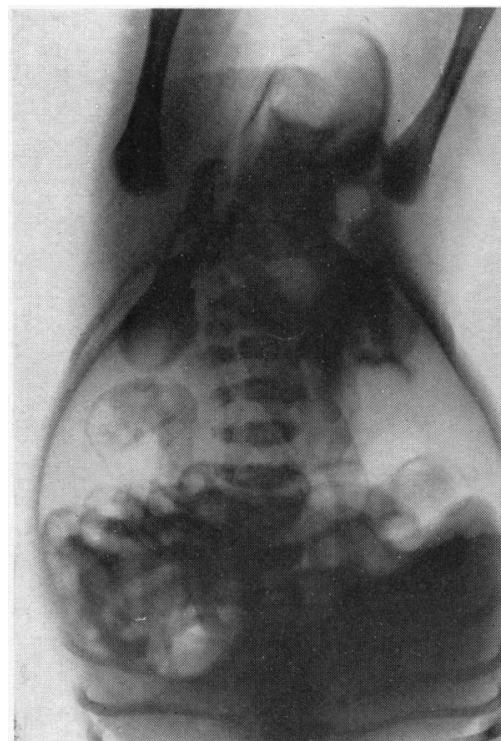

FIG. 3.

FIGS. 3 and 4.-Radiograph, antero-posterior and lateral in inverted position, showing gas in the scrotum and in the subcutaneous tissues of the lower abdominal wall. fairly good, but it rapidly deteriorated, and he died 27 hours later. During the post-operative period no urine was passed despite adequate hydration maintained by intravenous fluids.

NeCROPSY. The subcutaneous emphysema was still present in the lower abdominal wall and scrotum. The repair of the rupture in the anterior wall of the stomach was perfectly sound and there was no peritonitis. Histological examination showed that in all parts of the stomach wall the muscle coat was thinner than normal though this was more evident in the body and cardia than in the pyloric antrum. In the body the outer longitudinal coat was extremely thin and in places completely absent. The circular muscle was also considerably thinned, and in several sites there were complete gaps in the circular and longitudinal coats. The stomach wall in such areas

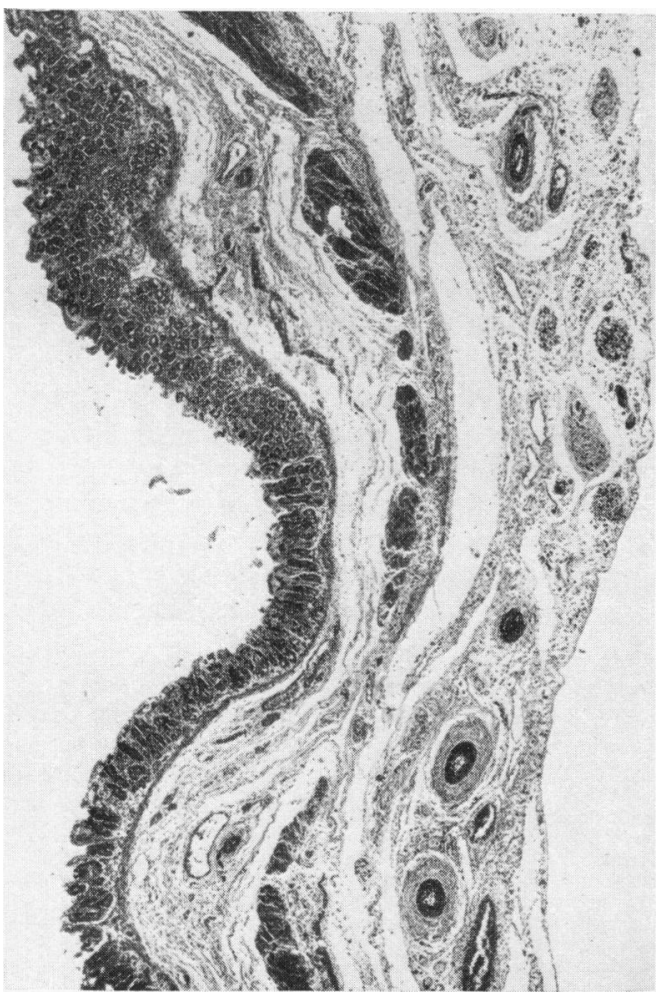

FIG. 5.-Histology of the gastric wall, showing areas of deficient gastric musculature. was composed only of mucosa, muscularis mucosa and the loose connective tissue of submucosa and subserosa (Fig. 5). At the cardia the oblique fibres were scanty. In the pyloric antrum the circular and longitudinal muscle coats were better developed and thicker than in the body though they were still thinner than normal.

The urinary tract had multiple developmental abnormalities (Fig. 6). A congenital bicuspid valve was present in the posterior urethra just distal to the verumontanum. The bladder was considerably hypertrophied but not dilated. The ureters were elongated and tortuous as a result of hypertrophy and dilatation. The ureteric pelves were not dilated. A stricture at the pelvi-ureteric junction on each side was impermeable to the finest probe and would have been thought to be a complete atresia but for the fact that the bladder contained a little urine.

Both kidneys were very small, each measuring $1.5 \times$

Fig. 6.-Necropsy specimen of the urinary tract, showing small kidneys, dilated ureters, hypertrophied bladder and urethral valve.

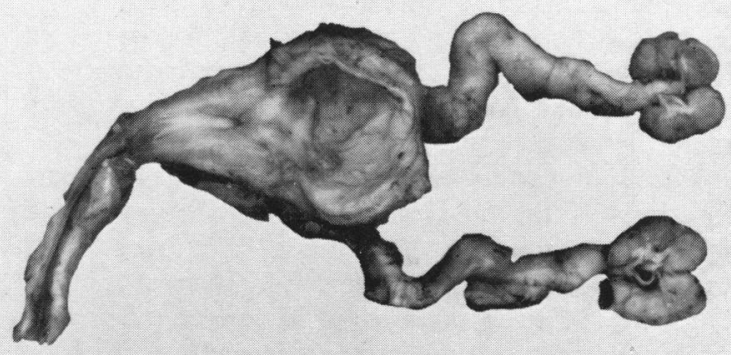


$0.8 \mathrm{~cm}$., and several small cysts were present in the cortices. Microscopically both kidneys showed defective development. Glomeruli were fairly numerous and comparatively normal. The secretory tubules were dilated and the collecting tubules were much reduced in number, most of the medulla being occupied by cellular connective tissue. Numerous cysts were present in both cortex and medulla and there were small masses of cartilage in the cortex (Fig. 7).

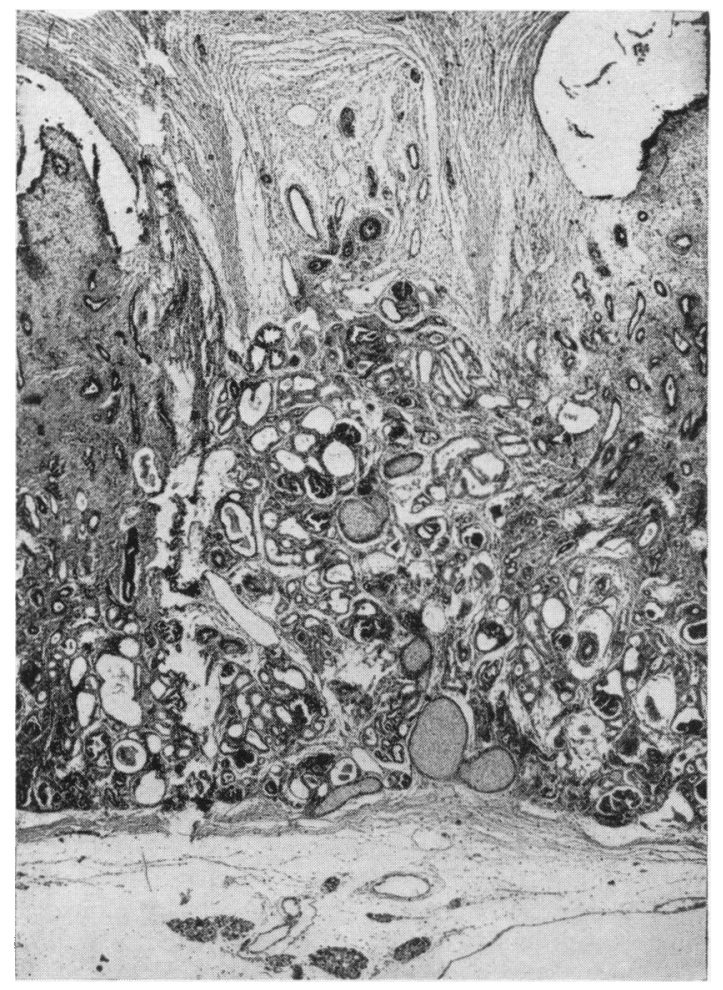

Fig. 7.-Histology of the kidney, showing cysts, dilated tubules and small masses of cartilage.

\section{Discussion}

Congenital abnormalities of two systems were present in this infant. Those involving the urinary tract were so severe as to cause death despite successful closure of the ruptured stomach. The facies characteristic of severe renal abnormalities first noted by Potter (1946, 1952a) was not seen in this case, but because of the anuria some gross renal disturbance was suspected.

There appear to be three causes of gastric perforation in the newborn. It may follow acute ulceration, though haematemesis is a more usual complication (Bird, Limper and Mayer, 1941; Guthrie, 1942). It may occur in congenital pyloric or duodenal atresia where there is distension of the stomach (Greene and Gose, 1953). Finally, it may be due to congenital muscle defects in the gastric wall. First described by Herbut (1943). More recently Braunstein (1954) reported five cases and referred to eight others. Since then successful surgical treatment of this type of perforation has been recorded (Northway, DeLano and Claytor, 1954). Morison (1952) considers that careful study of cases of alimentary perforation in this age group has led to more frequent recognition of localized congenital defects in the wall.

Perforation of the normal stomach has followed tube feeding (Potter, 1952b), but it is hard to believe that this could occur when a rubber tube is used with care, though it may happen with one made of polythene. Using a number 6 EG Jacques rubber catheter, stabilized by passing it through a narrow glass tube, we were unable to exert sufficient pressure to tear tissue paper. Nevertheless, rupture may occur when infants with defective gastric musculature are tube-fed, possibly by direct trauma, but more probably by sudden distension, and it seems likely that this happened in our case. Similarly, intragastric oxygen may be dangerous. It would be unreasonable to withhold these valuable procedures because of the remote risk of perforation of an abnormal stomach, but this danger should be remembered.

As there is always gas in the stomach, some usually escapes when gastric or duodenal perforation occurs. Large amounts of gas in the peritoneum will usually indicate a high perforation unless there is also an obstruction, but that this is not invariably so is shown by one of the cases reported by De Vel (1933) when a massive pneumoperitoneum followed rupture of the transverse colon in a newborn infant.

\section{Summary}

A case of rupture of the stomach in a newborn infant due to congenital defects in the gastric musculature is described. There were associated anomalies of the renal tract which were gross. The dangers of gastric intubation in such a case are mentioned. Radiological evidence of a massive pneumoperitoneum assisted in making a diagnosis.

We wish to thank Dr. J. O. Forfar and Mr. J. J. Mason Brown for permission to publish this case, and Dr. A. R. Macgregor for her very considerable help.

\section{REFERENCES}

Bird, C. E., Limper, M. A. and Mayer, J. M. (1941). Ann. Surg., 114, 526.

Braunstein, H. (1954). J. Pediat., 44, 55.

De Vel, L. (1933). Amer. J. Dis. Child., 45, 587.

Greene, W. W. and Gose, D. F. (1953). Ibid., 85, 47.

Guthrie, K. J. (1942). Archives of Disease in Childhood, 17, 82.

Herbut, P. A. (1943). Arch. Path., Chicago, 36, 91.

Morison, J. E. (1952). Foetal and Neonatal Pathology, pp. 311-12. London.

Northway, R. O., De Lano, R. H. and Claytor, A. A. (1954). Surgery, 35, 925 .

Potter, E. L. (1946). Amer. J. Obstet. Gynec., 51, 885.

(1952a). Pathology of the Fetus and the Newborn, pp. 363-4. Chicago.

(1952b). Ibid., p. 295. 